Paper ID \#19166

\title{
Student Driven Engineering Design Projects
}

\section{Ms. Christine Ann Newman, Johns Hopkins University}

CHRISTINE A. NEWMAN, M.B.A. Assistant Dean, Center for Educational Outreach, Whiting School of Engineering, Johns Hopkins University 3400 North Charles Street, Baltimore, MD 21218 Phone: (410) 516-4473; Fax: (410) 516-0264; email: cnewma13@jhu.edu

Professional Preparation: Virginia Polytechnic and State University B.S. Mechanical Engineering 1989 Marshall University MBA 1995

Appointments: 2010-Present Assistant Dean, Center for Educational Outreach, Whiting School of Engineering, Johns Hopkins University, Baltimore, MD 2007-2009 Director, Business Transformation Office, Single Family Mortgage Division, Fannie Mae, Washington DC 2005-2007 Program Pricing Director, Restatement Division, Fannie Mae, Washington, DC 2000-2005 Senior Program Manager, eBusiness Division, Fannie Mae, Washington, DC 1999-2000 Senior Product Manager, Essential Technologies, Inc., Rockville, MD 1998-1999 Product Manager, Essential Technologies, Inc., Rockville, MD 1994-1998 Manager, Air Programs, Apex Environmental Inc., Rockville, MD 1993-1994 Senior Environmental Engineer, Union Carbide Chemicals \& Plastics, Inc., Charleston, WV 1989-1992 Advanced Systems Engineer, Union Carbide Chemicals \& Plastics, Inc., Charleston, WV

Synergistic Activities: Project Leadership Team for STEM Achievement in Baltimore Elementary Schools (SABES), an NSF Funded Math Science Partnership with Baltimore City Public Schools Grant No. DUE1237992, 2012 - present. Co-Lead, STEM workgroup, Consortium for Urban Education, Baltimore, MD 2014-2015 Maryland State Department of Education STEM Equity workgroup 2014-2015 Professional Engineer, Commonwealth of Virginia, License No. 021864, 1996-2010 Board of Directors, Maryland Science Olympiad, 2010-present Champions Board, Mid Atlantic Girls Collaborative Network

\section{Dr. Carolyn Parker, Johns Hopkins University}

Carolyn Parker is a STEM education faculty member and researcher at the Johns Hopkins University School of Education. Her work appears in the Journal of Research in Science Teaching, Written Communication, and School Science and Mathematics and the edited volume: Research on Women in Education Series: Girls and Women in STEM Fields: A Never Ending Story.

Dr. Parker is a co-principal investigator for JHU's National Science Foundation STEM Achievement in Baltimore Elementary Schools (SABES) grant. The SABES grant is a 7.4 million dollar award that leverages the skills and resources of the schools, community, and businesses in three high-minority, lowresource Baltimore city neighborhoods. The goal is to integrate science into a child's world as opposed to bringing a student into the world of scientists.

\section{Ms. Alisha Nicole Sparks, Johns Hopkins University/Ctr for Educational Outreach}

Alisha N. Sparks works to educate and inspire parents to see their roles and responsibilities as a privilege in coordinating the raising and education of their children. Her current work as the Elementary STEM Program Manager with the Center for Educational Outreach at Johns Hopkins University allows her to capitalize on her 15 years of experience in formal and informal education to bring STEM educational experiences to students and parents in Baltimore. Her passion is working with young people and helping them to succeed as she firmly believes that "it is easier to build strong children than to repair broken men [and women]" as stated by Frederick Douglass.

\section{Prof. Michael L. Falk, Johns Hopkins University}

Michael Falk is Vice Dean of Undergraduate Education at Johns Hopkins University's Whiting School of Engineering where he has served on the faculty since 2008 as a Professor in the Department of Materials Science and Engineering with secondary appointments in Mechanical Engineering and in Physics and Astronomy. He holds a B.A. in Physics (1990) and a M.S.E. in Computer Science (1991) from Johns Hopkins University and a Ph.D. in Physics (1998) from the University of California, Santa Barbara. He has been 
twice selected as a visiting Chaire Joliot at the École Supérieure de Physique et de Chimie Industrielles at Paris Tech and has organized extended workshops on the physics of glasses and on friction, fracture and earthquakes at the Kavli Institute for Theoretical Physics. He has received several awards for his educational accomplishments, and in 2011 he received an award from the university's Diversity Leadership Council for his work on LGBT inclusion. His education research focuses on integrating computation into the undergraduate core curriculum. Falk also serves as the lead investigator for STEM Achievement in Baltimore Elementary Schools (SABES) an NSF funded Community Enterprise for STEM Learning partnership between JHU and Baltimore City Schools. 


\section{Impact of Student Driven Engineering Design Projects}

\section{Abstract}

As part of a National Science Foundation (NSF) funded Math and Science Partnership (MSP) between an urban, east coast, city school district and a private research university, city youth from three high-minority, high-poverty neighborhoods were taught the engineering design process both in-school and afterschool. Those in the afterschool program had STEM experts as mentors as well as a paid facilitator. They engaged in engineering projects from NPASS2 by Education Development Center, Inc. and from Engineering Adventure by the Boston Museum of Science for the first half of the year. Then, in the second half of the school year, they were given the opportunity to initiate their own student-driven projects. Students determined what problems and opportunities they saw in their own communities and chose one that they wanted to try to address using their engineering design skills. Third, fourth, and fifth grades students designed and built prototypes to attempt to use engineering to improve their community. For example, students designed portable homeless shelters, ultrasonic devices to free waste receptacles of rodents, and train track sensors to prevent accidents involving pedestrians. They then presented their design prototypes at a STEM showcase to their families, classmates, and teachers as well as their STEM expert mentors. Research indicates that afterschool program participants expressed higher interest in science and confidence in their capacity to do science than their classmates who were only engaging in STEM activities during the school day. These students' understanding of the "test" and "improve" steps of the engineering design process was particularly strong.

\section{Background}

This paper describes results from a five-year, National Science Foundation (NSF) funded Math and Science Partnership (MSP) that was initiated in an effort to improve educational outcomes in STEM disciplines within nine elementary schools situated in three neighborhoods of Baltimore. The partnership was specifically designed with a targeted focus on community engagement.

STEM Achievement in Baltimore Elementary Schools (SABES) focuses specifically on students in third through fifth grades. In addition to a school day component involving hands-on, projectbased curriculum and teacher professional development (PD), SABES offers a STEM-focused afterschool program at each school in which students work on student-developed, inquiry-based projects relevant to their communities. School day and afterschool students then showcase their work to their families and community members during biannual STEM Showcases.

SABES leverages the expertise of Johns Hopkins University (JHU) faculty, staff, post docs, graduate and undergraduate students as well as local STEM professionals and retirees. SABES involves partnerships with Baltimore City Public Schools as well as with community development corporations (CDCs) in each of the three neighborhoods. Volunteers serve as afterschool mentors, school day guest speakers and/or afterschool guest speakers. This corps of volunteers works within the partnership to help strengthen STEM expertise within the city schools in structured ways. Over the five years, SABES will have had an impact on approximately forty teachers and more than 2,200 third through fifth grade students. 
SABES was initiated when faculty and administrators from the Johns Hopkins University Whiting School of Engineering and faculty from the School of Education met to discuss possibilities for doing something meaningful for English language learner (ELL) students in Baltimore City Public Schools (City Schools) who were being pulled out of the limited science being taught in their elementary schools for ELL instruction. About a year before the NSF call for proposals was anticipated, the university team asked for a meeting with the teaching and learning office (T\&L) of City Schools to understand the district's needs around science education in elementary schools. Timing was such that the district was just initiating work funded by the state to develop K-5 curriculum for science with literacy integration and engineering design challenges targeted at schools designated as "underperforming" under the No Child Left Behind law. The district requested university assistance in this work. The university agreed to help without compensation. This began the development of the relationship between City Schools, the JHU School of Education, and the JHU Whiting School of Engineering. The bulk of the curriculum development was performed by a vendor with support from teachers in the district as well as T\&L and the university. Once the curriculum was developed, the T\&L staff recruited teachers for summer training and for piloting the curriculum in summer school. They then provided training and kits to teachers in 22 elementary schools to begin teaching the newly-developed science curriculum in their schools. During this period, the framework for the Next Generation Science Standards (NGSS) was released.

The partnership that had come together decided to compete for an NSF MSP focusing on the building of a "Community Enterprise for STEM Learning" as described in the NSF's call for proposals. Although the district wanted to swiftly develop a comprehensive program to serve all 130 elementary schools and K-5 grades, the limitations of the NSF MSP program required the number of schools and grades served to be targeted, in this case to nine schools and three grades. Furthermore, the team modified the scope of their work to incorporate the community by coupling in-school and afterschool learning with community events. School day programming focused on project-based curriculum and content-based PD for teachers. Afterschool programming focused on student-driven, community-based projects and integration of STEM experts from the broader community, including the School of Engineering and local engineering, health, and technology organizations, to mentor the students. Additionally, the team proposed STEM Showcases for the communities in which the schools were situated. At these STEM Showcases, students could be the experts, showing off what they had accomplished, and community members could learn and experience STEM through hands-on activities together. Schools were selected based on their location in high-need neighborhoods with active CDCs.

JHU, through either the Center for Engineering Outreach or the School of Education, had relationships with some schools already, but not with the other schools. Many, but not all, of the schools were "community schools" with externally-funded community liaisons working in the schools to coordinate partnerships. The university already had a prior relationship with one of the three CDCs and one of the out-of-school-time providers (OSTs) at the schools. As a consequence, relationships had to be built between a broad network of community organizations.

SABES was laid out to provide for a staged roll-out that would leverage the experiences of early adopters. The first year was a planning year. During this year, the curriculum was rewritten to align with the NGSS framework and the first content-based teacher PD course, known as a "STEM Academy," was developed. To provide expertise for teaching these STEM Academies, 
master teachers were educated through STEM certificates at local universities. Roles, responsibilities, and expectations were developed. The second year of the grant was the first year of school implementation. The rollout was to one school in each of the three neighborhoods and their OSTs and CDCs. During each subsequent year, SABES incorporated one more school in each of the three neighborhoods until the full cohort of nine schools were participating. SABES will continue to be NSF funded through two years of full implementation involving all nine schools, three CDCs and six OSTs.

Training and Roles of facilitators, coaches and mentors

Table 1: Facilitators, coaches and mentors in SABES OST

\begin{tabular}{|c|c|c|c|c|}
\hline Role & Workload & $\begin{array}{l}\text { Main } \\
\text { Responsibilities }\end{array}$ & Training & Backgrounds \\
\hline Facilitator & $\begin{array}{l}\text { Engages up to } \\
15 \text { students in } \\
\text { engineering } \\
\text { design } \\
\text { projects }\end{array}$ & $\begin{array}{l}\text { Plans lessons, } \\
\text { purchases } \\
\text { materials, } \\
\text { coordinate with } \\
\text { mentors, schedules } \\
\text { guest speakers and } \\
\text { field trips as } \\
\text { needed }\end{array}$ & $\begin{array}{l}\text { Initial training } \\
\text { followed by } \\
\text { monthly PD }\end{array}$ & $\begin{array}{l}\text { Over half were teachers } \\
\text { Of these, } 1 / 3 \text { taught in } \\
\text { school curriculum as } \\
\text { well as OST }\end{array}$ \\
\hline Coach & $\begin{array}{l}\text { Works with 3- } \\
6 \text { facilitators } \\
\text { (typically 1-2 } \\
\text { schools) }\end{array}$ & $\begin{array}{l}\text { Observes and } \\
\text { provides feedback } \\
\text { to facilitator } \\
\text { Prepares and } \\
\text { delivers PD }\end{array}$ & $\begin{array}{l}\text { Program } \\
\text { manager } \\
\text { provided initial } \\
\text { training and } \\
\text { feedback from } \\
\text { facilitators and } \\
\text { project } \\
\text { leadership } \\
\text { provided input } \\
\text { for adjustments } \\
\text { to coaching }\end{array}$ & $\begin{array}{l}\text { Educators and STEM } \\
\text { experts }\end{array}$ \\
\hline $\begin{array}{l}\text { STEM } \\
\text { Mentors }\end{array}$ & $\begin{array}{l}\text { Groups of 6-8 } \\
\text { mentors take } \\
\text { turns working } \\
\text { in pairs } \\
\text { weekly with } \\
\text { the same } \\
\text { facilitator and } \\
\text { their students }\end{array}$ & $\begin{array}{l}\text { Encourage } \\
\text { students through } \\
\text { the EDP, be role } \\
\text { models and } \\
\text { mentors } \\
\text { Share STEM } \\
\text { expertise when } \\
\text { relevant, support } \\
\text { development of } \\
\text { critical thinking } \\
\text { skills }\end{array}$ & Initial training & $\begin{array}{l}\text { STEM experts from } \\
\text { university, government } \\
\text { and industry typically } \\
\text { with no K-12 teaching } \\
\text { experience }\end{array}$ \\
\hline
\end{tabular}


The role of the paid facilitator (see Table 1) within the OST setting was to engage the students in the lessons and to guide them through the engineering design process (EDP) without dictating to students what to do or how to do it. This required a facilitator with skills in classroom management who could be part director, part cheerleader. Despite the semi-structured nature of the OST environment, the facilitators were required to plan their lessons. PD was provided to these facilitators. They were also the ones to purchase materials based on student ideas, to identify and host guest speakers, to schedule relevant field trips, to husband the student-driven projects to fruition, coordinate with the mentors, and take attendance.

Facilitators had a variety of backgrounds (see last column of Table 1). Over half were teachers (of the 78 facilitators over the four years, 41 were teachers or former teachers and seven were certified teachers). Three were para-professional educators, three were detectives, seven were undergraduate students (five with a STEM major, two without), six were in youth development, two were afterschool STEM educators, one was a STEM postdoc, one was a guidance counselor, one was in security, one was an artist. Nine had no teaching or STEM experience and reported no other occupation. Of the 41 teachers, 14 of them were teaching the science curriculum to the same students during the school day. Turnover of the facilitators was high and presented one of the most significant logistical challenges of administering the SABES OST program.

The SABES OST program model paired 15 students by grade level with one facilitator (see Table 1). Volunteer STEM mentors visited the afterschool class in pairs once a week rotating weekly so that six to eight mentors came through over the course of three to four weeks. Often, a cohort of mentors also worked together in a university lab or in the same organization. This helped to facilitate coordination between mentors. The role of the mentor was to build relationships with the students and the facilitator, to encourage and guide students during STEM activities, and to support the learning of critical thinking skills and the EDP. Ideally, they would also have a chance to be role models for colle ge and STEM careers.

After the first year of implementation, significant modifications were made to the SABES OST program in response to leadership team observations and formative evaluation. Initially a oneday training was held at the beginning of the school year for the facilitators and mentors and then again for facilitators alone before the student-driven projects. It was observed that the facilitators could benefit from more support in maintaining a well-managed classroom that promoted student-agency. At the same time, mentors indicated that monetary incentives were unnecessary since they participated in the program for personal enrichment. As a result, after consultation with NSF, funds were freed up that enabled the hiring of OST coaches. Coaches would observe and provide feedback to the facilitators and would host required monthly PD (see Table 1). Expectations were clarified that facilitators would spend an hour preparing for afterschool sessions. In the second year of implementation, three coaches assisted six schools, and in the third year six coaches assisted nine schools. In the final year, there were eight coaches serving nine schools. Some of the coaches worked at multiple schools, some at only one, depending on their availability. The coaches' backgrounds included educators, a chemist, working engineers, and a college graduate with a biology degree (see last column of Table 1). Together, they and the program manager developed the training based on the needs observed by the coaches and on the feedback provided by facilitators in monthly surveys. After the introduction of coaching, training of mentors also shifted from a single half-day session to local training by coaches and facilitators at the school site. 


\section{Data Collection and Research Results}

This study used a mixed-methods approach to better understand the impact of the SABES's outof-school time (OST) program. The question was asked, "Do the students who participate in the SABES OST program report enhanced motivation, understanding, and career aspirations around engineering and the engineering design process?"

\section{Student Motivation and Career Aspiration Survey Analysis}

Table 2 includes responses from 1,566 students in third through fifth grade in 15 schools. This analysis takes advantage of the staggered implementation of SABES among the participating schools. Spring 2015 survey responses for third through fifth grade children compare students in six comparison schools, nine SABES schools, and a subset of children in SABES schools - those who attended the OST program for at least 20 days. For this analysis, the baseline measures for three SABES schools that had not yet adopted the SABES program are included with the six comparison schools.

Four of the six participating SABES schools provided sufficiently detailed records to identify daily attendance at SABES OST during the 2014-2015 school year. At these four schools, 154 students attended at least one day of the SABES OST program, 70 for at least 20 days. Therefore, for the purpose of this analysis, these 70 students who attended the SABES OST program for at least 20 days - and as many as 50 days - are considered SABES OST students.

The students who attended the six comparison schools and the three pre-implementation SABES schools are reported in the first column of Table 2. The second column of Table 2 shows the survey responses for all students in the schools where SABES had been implemented for at least one year, and the third column reports the values for the SABES OST students. The results for non-OST students in SABES schools are not shown, but they are statistically indistinguishable from the overall school means.

The first four questions in Table 2 are selected components of the nine-item Expectancy-ValueCost (EVC) scale that was developed by another NSF-funded research team (Kosovich, Hulleman, Barron, \& Getty 2015) ${ }^{1}$. Students provided answers on a five-point scale that was intended to be developmentally appropriate for elementary school students (e.g., "Not at All Sure" to "Completely Sure" with 3 equivalent to "Sure"). The survey also included the four occupational questions shown below these in Table 2. For these measures, the proportion of students who answered the question "yes" was reported.

Column four in Table 2 reports the standardized difference (mean difference/standard deviation) between the comparison schools and the SABES schools. Column five in Table 2 reports the standardized difference between the non-OST students in SABES schools (not shown) and the SABES OST participants. 
Table 2. Survey Response Means for Comparison School Students, SABES Students, and OST Participants

\begin{tabular}{|c|c|c|c|c|c|}
\hline & & & & Stand. & ference \\
\hline & $\begin{array}{l}\text { Compar. } \\
\text { Schools }\end{array}$ & $\begin{array}{l}\text { SABES } \\
\text { Schools }\end{array}$ & $\begin{array}{c}\text { OST } \\
\text { Participants }\end{array}$ & $\begin{array}{c}\text { Compar. } \\
\text { vs. } \\
\text { SABES }\end{array}$ & $\begin{array}{c}\text { SABES } \\
\text { Non-OST } \\
\text { vs. OST }\end{array}$ \\
\hline $\begin{array}{l}\text { How sure are you that you can learn } \\
\text { science this year? }\end{array}$ & 3.95 & 4.19 & 4.36 & $0.23^{* *}$ & $0.22 \dagger$ \\
\hline How important is science to you? ${ }^{\circ}$ & 4.11 & 4.15 & 4.30 & 0.04 & 0.20 \\
\hline $\begin{array}{l}\text { Overall, how interested are you in } \\
\text { learning about science? }\end{array}$ & 4.12 & 4.08 & 4.34 & -0.03 & $0.21 \dagger$ \\
\hline How much do you like science? ${ }^{\circ}$ & 4.12 & 4.09 & 4.39 & -0.02 & $0.24 \dagger$ \\
\hline I know what engineers do in their jobs & 0.48 & 0.53 & 0.63 & $0.10^{*}$ & 0.15 \\
\hline I would like to be a scientist & 0.37 & 0.44 & 0.47 & $0.16^{\star \star}$ & 0.10 \\
\hline I would like to be an engineer & 0.30 & 0.38 & 0.39 & $0.18^{* *}$ & 0.01 \\
\hline I would like a job where I invent things & 0.27 & 0.33 & 0.33 & $0.13^{*}$ & 0.05 \\
\hline $\mathrm{N}$ & 893 & 673 & 70 & & \\
\hline
\end{tabular}

The standardized difference for "How sure are you that you can learn science this year?" between comparison schools and SABES schools is 0.23 and is statistically significant. The OST students reported a mean that was higher still (4.36) which corresponds to a marginally significant standardized difference compared to non-OST participants in the same school (0.22).

There is evidence that students in schools where SABES OST has been implemented for at least one year report higher levels of motivation and STEM career orientation than students in the comparison schools and schools that had not yet adopted SABES. Students who participate in the OST program report even higher levels of motivation.

\section{Student Interviews About the Engineering Design Process}

The research around SABES is a mixed-method approach. To more deeply understand how the students were thinking about engineering design, researchers interviewed twelve students who had attended the SABES OST program. The twelve students who were selected for the interview had attended the SABES OST program at a well-implemented site for two consecutive years. SABES's research and evaluation team completed regular visits at each site. They documented facilitator and student attendance, noted the general instructional climate, observed the engagement of the facilitators and students, and assessed instruction. This site was determined to have the best-run SABES OST program of the sites because students attended regularly, the climate was positive, and almost all students were engaged in the day's activities during the site visits. 
Using an instrument developed by Hsu, Cardella, and Purzer (2012) ${ }^{2}$, ten girls and two boys were interviewed. Nine of the girls identified as African American, one girl identified as Asian, and both boys identified as African American. Each interview was video recorded, transcribed, and analyzed by two independent coders. The two coders then worked together to develop consensus around the developed assertions for each interview. The coding process allowed SABES researchers to identify themes and draw conclusions about the students' understanding of the Engineering Design Process (EDP).

The analysis revealed that the SABES OST program supported students in developing a deep understanding of the EDP. All twelve of the students recognized the EDP and could describe it in detail. Moreover, the students described the importance of community-focused, student-driven projects in supporting their understanding and application of the EDP. Of interest was that eleven of the twelve students were able to articulate the "improve" phase in great detail. Students were quite articulate about the notion that the EDP is a cycle that may need to be repeated, especially to improve on the project; that is, they understood the iterative nature of the EDP.

In addition, the students who had grounded their understanding of the EDP in contexts to which they could relate in personal and meaningful ways showed greater understanding of the EDP and of engineering in general. Furthermore, the students the SABES researchers worked with were able to articulate how engineering applied to their lives beyond the confines of school.

Importance of student driven community based projects

Students tackled problems in their community that were quite challenging even to adults. These included: homelessness, rodent infestations, graffiti prevention, trash collection, train safety, stray cat protection, back injuries due to heavy backpacks, security issues, soundproofing open layout classrooms, and protection from asthma. Some of these problems were specific to students in and around their school; some were focused on perceived needs of their neighborhood, and some were more far-reaching. The common thread was that the students identified the problem they wanted to solve by investigating their school and community first. Students talked about possible solutions and chose a project upon which to focus. Students undertook research to learn more about their problem and existing solutions.

The student-driven aspect of SABES was important for motivating the students to investigate their problem and various possible solutions. Instead of being directed by an adult, students thought, discussed, and made decisions together. They decided upon relevant field trips and guest speakers in order to provide context to inform SABES.

The community-based aspect of SABES was crucial for establishing in the minds of students, teachers, parents, and community members that STEM skills are relevant for their community now and in the future. Instead of being an academic exercise, each student engineering design project was a practical attempt to envision the potential benefits to the community.

For example, one school maintained a school garden. The fourth grade students decided to work on a composting project that would repurpose waste from the cafeteria. The students researched composting, learned about composting from a guest speaker and field trip, and tested methods of composting on small batches. They ultimately piloted their plan during a lunch period with food waste from the cafeteria. 
Another school's fourth graders noticed stray cats running in the alleys, hiding under cars, and searching for food during their community walk. The students had a lot of questions about these cats. Where do they live? What do they eat? Where do they go when it is raining or snowing? They decided to build a seasonal cat shelter for the feral cats. They undertook internet research regarding the best ways to design and build a seasonal cat shelter. They investigated different material and shelter styles that were favored by cats. Using recycled materials, the groups created model shelters to test their designs. A guest speaker from the Maryland SPCA came to speak to their class about proper animal care and guidelines regarding how to approach feral animals. The visiting experts also provided feedback on the student designs and supplied cat food and water bowls to incorporate into the project. The students learned that cats like to climb, so they built insulated shelters with two floors. Student teams of four each built their own shelter and used paper towel tubes to create cat toys. Students created maps of the neighborhood to determine the best placement for the shelters.

Conclusion

Experiences implementing a semi-structured OST program in an urban school district demonstrate that adopting an approach in which students engage in self-directed, communityfocused projects can have measureable benefits. These benefits include increased confidence and interest in science and engineering pursuits. Students also acquire a meaningful understanding of the engineering design process, and particularly its iterative nature. The community contextualization has been observed to provide further benefits by making the relevance of STEM a central feature of the student engagement. Further study is needed to determine if this also facilitates communication between students, families, and community members, positioning these students as STEM ambassadors able to relate the value of engineering to their community. 


\section{References}

${ }^{1}$ Kosovich, J. J., Hulleman, C. S., Barron, K. E., \& Getty, S. (2015). A Practical Measure of Student Motivation: Establishing Validity Evidence for the Expectancy-Value-Cost Scale in Middle School. The Journal of Early Adolescence, 35(5-6), 790-816.

${ }^{2}$ Hsu, M., \& Cardella, M. E., \& Purzer, S. (2012, June), Elementary Students' Engineering Design Process Knowledge: Instrument Development and Pilot Test Paper presented at 2012 ASEE Annual Conference \& Exposition, San Antonio, Texas. https://peer.asee.org/21270 